\title{
BIOLOGGING IN THE GLOBAL OCEAN OBSERVING SYSTEM
}

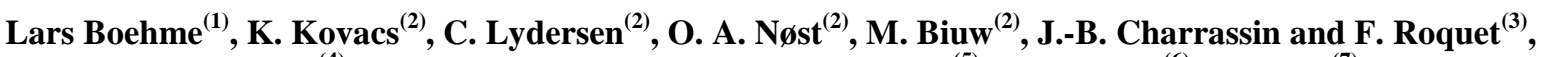
C. Guinet $^{(4)}$, M. Meredith, K. Nicholls and S. Thorpe ${ }^{(5)}$, D. P. Costa ${ }^{(6)}$, B. Block ${ }^{(7)}$, M. Hammill and G. Stenson ${ }^{(8)}$, M. Muelbert ${ }^{(9)}$, M. N. Bester ${ }^{(10)}$, J. Plötz and H. Bornemann ${ }^{(11)}$, M. Hindell ${ }^{(12)}$, S. Rintoul ${ }^{(13)}$, P. Lovell and M. A Fedak ${ }^{(1)}$

${ }^{(1)}$ NERC (Natural Environment Research Council) - Sea Mammal Research Unit, Scottish Oceans Institute, University of St Andrews, East Sands, St Andrews KY15 5QJ United Kingdom, Email: lb284@st-andrews.ac.uk; pl7@st-andrews.ac.uk; maf3@st-andrews.ac.uk

${ }^{(2)}$ Norwegian Polar Institute, Polar Environmental Centre Fram Centre, Hjalmar Johansens, gt. 14, NO-9296 Troms $\phi$, Email:kit.kovacs@npolar.no; christian.lydersen@npolar.no; ole.anders.nost@npolar.no; martin.biuw@npolar.no

(3) 402/Laboratoire d'Océanographie et du Climat, Département Milieux et Peuplements Aquatiques, Muséum National d'Histoire Naturelle, 43 rue Cuvier, 75231 Paris Cedex 05, France, Email: jbc@mnhn.fr

(4) Centre d'Études Biologiques de Chizé, Centre National de la Recherche Scientifique, BP 14, Villiers-en-Bois, F-79360 Beauvoir sur Niort, France, Email: christophe.guinet@cebc.cnrs.fr

${ }^{(5)}$ British Antarctic Survey, High Cross, Madingley Road, Cambridge CB3 OET, United Kingdom, Email: m.Meredith@bas.ac.uk; k.nicholls@bas.ac.uk; seth@bas.ac.uk

${ }^{(6)}$ Center for Ocean Health, Institute of Marine Sciences, Long Marine Laboratory, University of California, 100 Shaffer Road, Santa Cruz, CA 95060 USA, Email: costa@biology.ucsc.edu

(7) Hopkins Marine Station, Stanford University, Oceanview Boulevard, Pacific Grove, CA 93950 USA, Email: bblock@stanford.edu

${ }^{(8)}$ Fisheries and Oceans Canada, P.O. Box 5667, St. John's, Nfd A1C 5 X1 Canada, Email: Garry.Stenson@dfo-mpo.gc.ca; Mike.Hammill@dfo-mpo-gc.ca

(9) FURG (Fundação Universidade do Rio Grande), Dept. of Oceanography, PPGOB (Programa de Pós-graduação em Oceanografia Biológica), Depto de Oceanografia, Campus Carretros - CP 474, 96.201-900 Rio Grande RS BR, Email: mamíferos@furg.br

(10) Mammal Research Institute, Dept. of Zoology and Entomology, University of Pretoria, Zoology Building Room 3. 11, Pretoria 0002 ZA, Email: Marthan.Bester@zoology.up.ac.za

(11) Alfred Wegener Institute for Polar and Marine Research, Postfach 1201 61, 27515 Bremerhaven, Germany Email: Joachim.Ploetz@awi.de

(12) Antarctic Wildlife Research Unit, School of Zoology, University of Tasmania, Private Bag 5, Hobart, Tasmania, 7001, Australia, Email: Mark.Hindell@utas.edu.au

(13) CSIRO, (Commonwealth Scientific and Industrial Research Organisation), GPO Box 1538, Hobart, Tasmania 7001 Australia, Email: steve.rintoul@csiro.au

\section{ABSTRACT}

Miniature electronic data recorders and transmitters have revolutionized the way we study animals over the past decades, particularly marine animals at sea. But, very recently, animal-borne instruments have also been designed and implemented that provide in situ hydrographic data from parts of the oceans where little or no other data are currently available (even from beneath the ice in polar regions). Ocean data is delivered from animal-borne instruments via satellites in near real-time, which would enrich the Global Ocean Observing System if animal-borne instruments were deployed systematically. In the last 10 years, studies involving more than 10 countries (Australia, Brazil, Canada, France, Germany, Greenland, Norway, South Africa, UK, USA) have demonstrated how highly accurate oceanographic sensors, integrated into standard animal, biologging instruments, can provide data of equal or better quality than XBT/XCTD (Expendable Bathythermograph / Expendable Conductivity Temperature and Depth) data. Here, we
\end{abstract}

present some of the pioneering studies and demonstrate that we now have enough information for many marine species to predict where they will go - within reasonable limits. Thus, we can direct sampling effort to particularly interesting and productive regions and maximize data return. In the future, biologging could certainly play an important part in the Global Ocean Observing System, by providing complementary data to more traditional sampling technologies - especially in the high latitudes. This paper will make a core contribution to the Plenary Sessions 4A, 4B and 5A and will be relevant to $2 \mathrm{~A}, 2 \mathrm{~B}$ and $3 \mathrm{~A}$.

\section{THE HISTORY OF BIOLOGGING IN OBSERVING THE OCEANS}

Enlisting marine animals as physical-ocean sampling platforms is not a new idea. The earliest published reference to this concept is from 1970 [1]. However, until recently, no one had developed the technology to allow viable collection of high-quality hydrographic information in this manner. But, now such instruments 


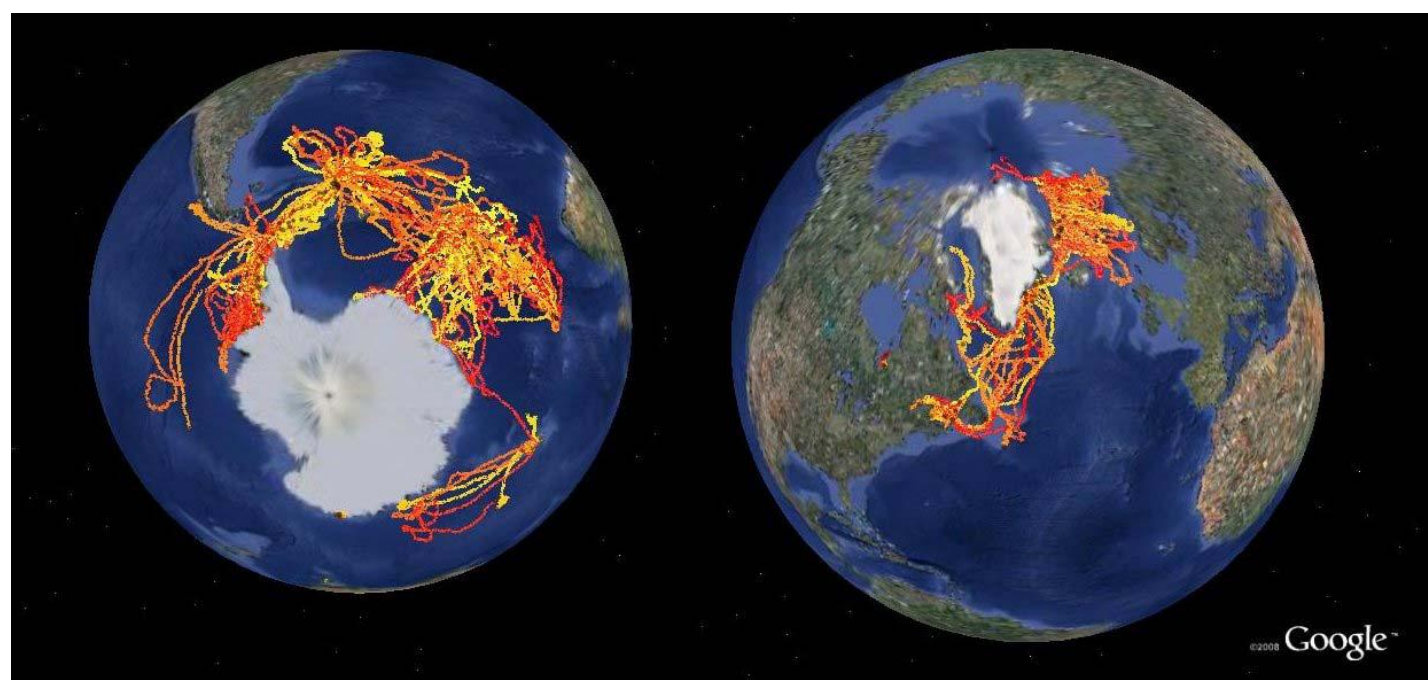

Figure 1: Some of the tracks of tagged animals so far collected by the MEOP project since July 2007 in Antarctica (left) and in the Arctic (right).

do exist, and they have the potential to collect information about the oceans that is not only relevant to studying the ecology of animals carrying the instruments (e.g., [2, 3 and 4]), but also for studying the physical structure of the oceans (e.g., $[5,6,7,8,9$ and 10])

Some behavioural tags, which also record ocean temperature and pressure use simple sensors with medium accuracy, normally less than $\pm 0.1^{\circ} \mathrm{C}$ (e.g. $[5,6$, 11, 12 and 13]). However, such measurements become important in regions where traditional oceanographic measurements are scarce. For example, Sokolov et al. [13] used data from temperature-only loggers deployed on king penguins to track the Polar Front south of New Zealand.

But marine biologists saw the potential of getting high accuracy data from the immediate environment of an animal [2 and 5] and developed better sensors and instruments, which not only record temperature, but also conductivity and are able to relay these data via satellites [2 and 14]. Here, we will focus on such instruments, which have the greatest potential for the Global Ocean Observing System.

Lydersen et al. [2] were the first research group to attach such high accuracy oceanographic instruments measuring temperature and salinity to a marine mammal species. Data was collected using conductivity-temperature-depth satellite relay data loggers (CTD-SRDLs) attached to the white whales in their study and were used to investigate the oceanographic structure of a freezing Arctic fjord in Svalbard during early winter 2001. A year later, temperature-profiling instruments were attached to ringed seals in the same region and these provided, via
Argos, amore than 2300 temperature profiles over a 4month period in areas that were at times $90-100 \%$ icecovered [15].

The first large scale study that deployed CTD-SRDLs was the 'Southern Elephant seals as Oceanographic Samplers' (SEaOS) project ${ }^{1}$ in the Southern Ocean. The programme was an international collaboration with partners from the UK, France, USA and Australia. From the austral summer of 2003/04 until the end of 2005, SEaOS collected more than 24000 temperature profiles to depths up to $2000 \mathrm{~m}, 90 \%$ of which had corresponding salinity profiles. Charrassin et al. [9] showed that this approach can provide a 30-fold increase in the availability of temperature and salinity profiles from the sea-ice zone, while Boehme et al. [8] highlighted the complementary nature of animal-borne sensor data to that from other ocean observation approaches and showed how their value is maximized when various types of sampling are integrated. SEaOS also demonstrated the usefulness of animal-borne data for studying upper ocean variability [8 and 10].

Based on the success of SEaOS, a new project was set up as part of the International Polar Year (2007 to 2010). 'Marine Mammals Exploring the Oceans - Pole to Pole' (MEOP) involved 10 countries (Australia, Brazil, Canada, France, Germany, Greenland, Norway, South Africa, UK and USA) and will in combination deploy approximately 150 state-of-the-art animal-borne CTD-SRDLs on strategically chosen, deep-diving marine mammal species to explore their current movement patterns, behaviour and habitat utilization and to sample oceanographic profiles in both North and South polar regions (Fig. 1).

\footnotetext{
${ }^{1}$ http://biology.st-andrews.ac.uk/seaos/index.html
} 
Another project, the Tagging of Pacific Predators (TOPP) $2^{2}$, began in 2000 and involves 23 different species that occupy the Pacific Ocean. Some of these marine species are equipped with sensors to measure temperature, light and pressure or with CTD-SRDLs. More information about TOPP is contained in the white paper by Costa et al [16]. There are also smaller national projects in different countries using animalborne instruments on other species to link animal behaviour to their immediate physical environment. One example is the tagging of Weddell seals by the British Antarctic Survey and partners. This ongoing project started in 2007 when four CTD-SRDLs were deployed in the Weddell Sea. Instruments relayed data during the winter when seals were some $3000 \mathrm{~km}$ inside the pack ice edge, staying on or close to the continental shelf [17].

As the data from the past decade illustrate, the spatial and temporal coverage that can be achieved using animal-borne instruments make them suitable for integration into the Global Ocean Observing System. Some of the animal-borne instruments are also capable of real-time data transfer that makes them a valuable tool for short-term weather and ocean forecast systems.

\section{ANTICIPATING THE ACHIEVEMENTS OF BIOLOGGING IN AN OCEAN OBSERVING SYSTEM.}

Animal-borne oceanographic instruments have enabled us to obtain in situ datasets with high spatial and temporal resolution even in regions that are seasonally ice-covered (Fig. 2). Some species are wide-ranging (Fig. 1), while others can generate long Eulerian series (Fig. 2) and [18]. Therefore, they can fill 'blind spots' in the sampling coverage of existing ocean observing systems.

Of course, animal samplers do present some additional challenges in addition to the new opportunities. They do not sample randomly, nor do they perform pre-set transect coverage in the manner that can be accomplished with ships or gliders. As with Argo floats, the exact locations of data collection cannot be pre-determined. However, today we have enough information on many species to predict where they are likely to go within reasonable limits. Appropriate choice of study species and even specific age and sex group, can allow us to pre-define the timing and spatial extent of sampling to a large degree and we can even predict the likely number of profiles, including likely diving depths, that will be gathered during a specific time interval. For example, elephant seals travel large distances and, depending on the programming of the instrument, between 2 and 3 CTD profiles a day are received and these are usually separated by less than 40 $\mathrm{km}$ providing a station spacing similar to ship-based transects (Fig. 3) [8,19]. Weddell seals do not travel far from the usual deployment sites, but their instruments delivered 4 to 5 CTD profiles per day from the water column beneath the pack ice and the station spacing was less than $6 \mathrm{~km}$ for more than $90 \%$ of the data gathered [17].

Unlike Argo floats, animals often move relatively rapidly in a directed fashion and can thus deliver transects of nearly contemporaneous data (Fig. 3). Their tracks often cut across frontal regions as they travel between breeding, foraging and resting locations [4 and 19]. They can direct sampling effort to particularly interesting and productive regions as they adaptively sample their environment based on previous experience. This has the added benefit that individuals are likely to retrace previous tracks, and can therefore provide repeat sections over a variety of time frames (Fig. 3). Some species penetrate deep into polar regions in ice-covered areas where cloud cover can limit the applicability of remote sensing, and where most profiling floats and ships cannot operate [9 and 17]. Despite the necessary limitations imposed by small size, power restrictions and limited communication bandwidth, the specific characteristics mentioned above make animal-borne sensors advantageous in many instances, especially when used in a complementary way with other observational approaches [8].

Because of the 'adaptive' nature of the way animals sample their environment, it will always be necessary to incorporate data from them into broader observing systems such as drifting buoys, ships of opportunity etc [8]. It also seems likely that animal-borne instruments will never provide data of the quality achieved by the best ship-borne instruments. But if appropriate specifications of accuracy and precision are provided, the constraints involved in developing and using this approach can be overcome and animal-borne oceanographic sensors will provide an extremely valuable complement to other ocean-sampling technologies.

\section{TECHNICAL ISSUES}

There are a number of particular constraints that must be overcome to realize the potential of animal-borne oceanographic sampling devices. Some are common to all forms of telemetry and data logging (e.g. floats and gliders), while some are specific to oceanographic sampling from animals. The most fundamental constraint to the use of animals as platforms is the size of the instrumentations package that they can carry.

\footnotetext{
${ }^{2}$ www.topp.org
} 

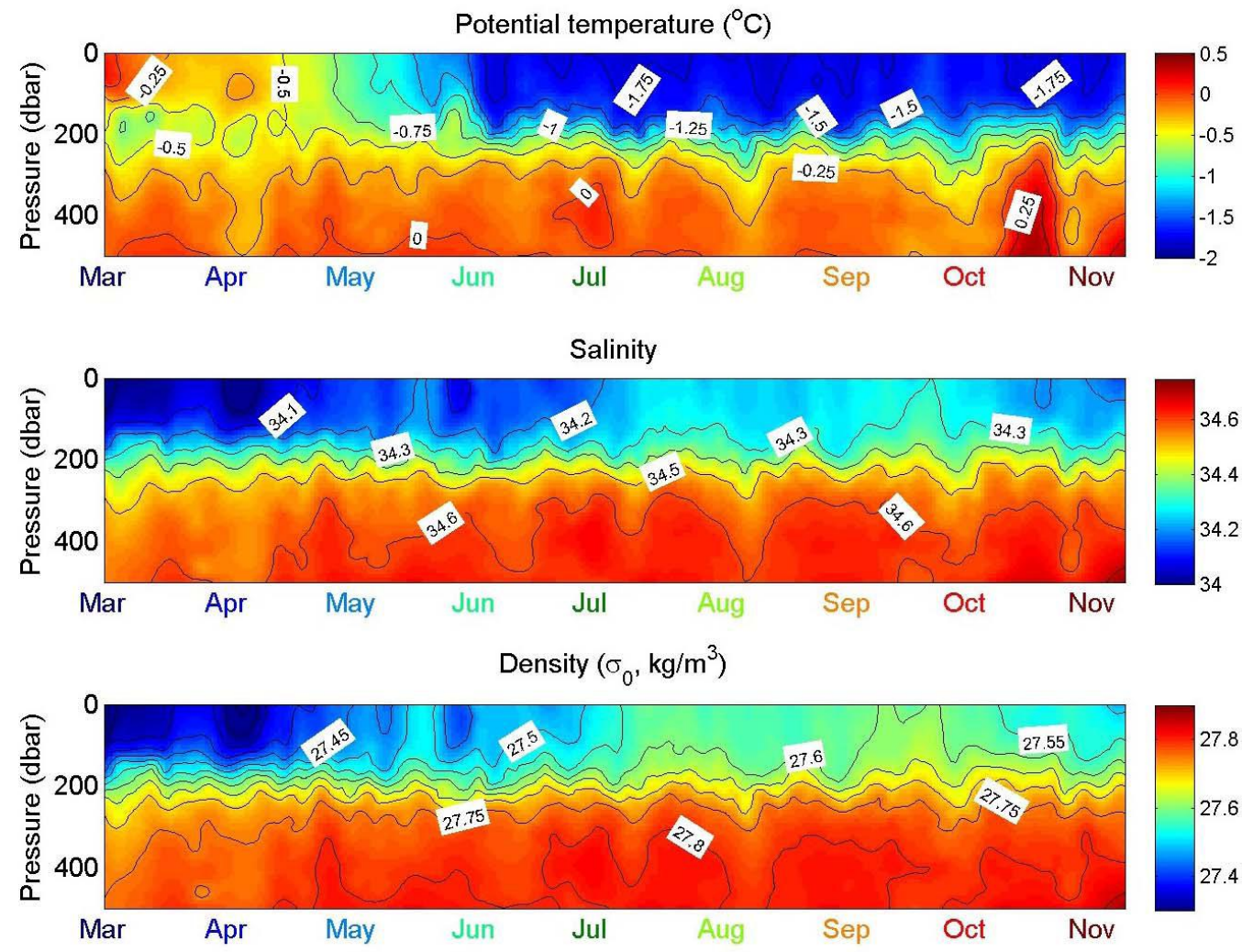

Figure 2: Time series of potential temperature (top), salinity (middle) and potential density $\left(\sigma_{0}\right)$ for the upper ocean near the South Orkney Islands during 2007 (from Meredith et al., in press [18]

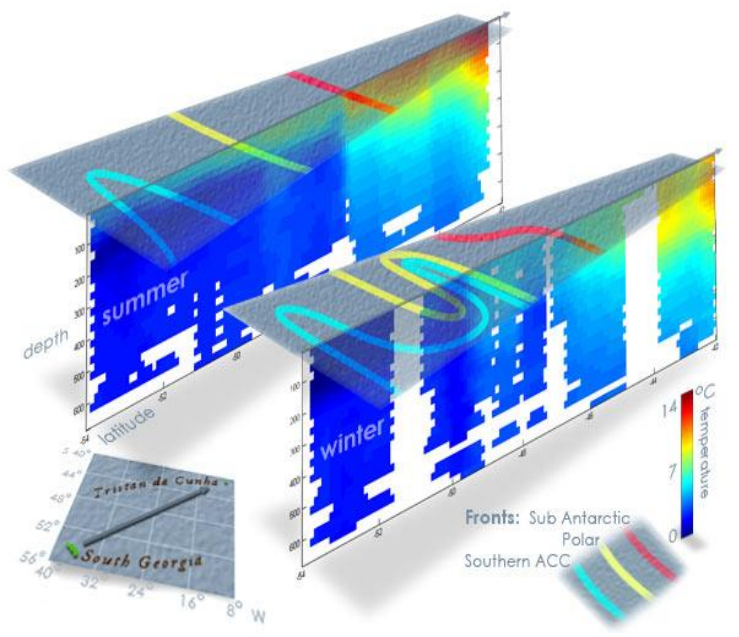

Figure 3. Two temperature sections recorded by one elephant seal tagged on the island of South Georgia, retracing its previous migration pattern [20].

While the 'rule of thumb' for animal-borne instruments dictates that they weigh no more than $2 \%$ of the total body weight, subsequent studies have shown the importance of species-specific considerations. Previous studies deploying animal-borne instruments, weighing just over $250 \mathrm{~g}$ in seawater (usually less than $0.3 \%$ of the bodyweight), on a large number of seal and turtle species have shown no detectable changes in behaviour, feeding or reproductive success. Nevertheless, future developments still have to try to minimize the size of instruments in order to minimize any possible effects.

\subsection{Communication and Energy}

Keeping instrument size to a minimum limits the battery size, and hence the energy budget of the instrument. Some instruments are archival tags and only log data. When the tag/animal is retrieved at the end of the deployment, the oceanographic information is downloaded and stored for future use.

However, many marine animals travel on a global scale and retrieval of instruments is not always possible. In these cases, the only option is to relay the data via a telemetry system (e.g. Argos, Iridium, or GSM) but every bit of information that is transmitted uses some of the energy contained in the battery [14] and therefore such transmitters are sometimes relatively energy demanding when compared to the sensors.

Another constraint is the bandwidth of the available communication platforms and their spatial coverage. The most common system currently used for tracking 
wide-ranging animals is the Argos satellite system [21]. Its global coverage makes it suitable for longmigration patterns, but the very strict limit on the number of bits allowed per relayed data message, the strict message structure combined with the fact that animals are only briefly and infrequently at the surface places unusually tight limits on bandwidth. (E.g. elephant seals typically spend only $10 \%$ of their time at the surface in two minute segments.) The bandwidth restriction is compounded by the fact that satellites are not always visible. Because there is presently no handshaking with Argos, messages have to be sent several times to ensure a sufficient probability of reception and this demands complex data collection software and extreme data compression to make systems effective for long deployments. This demands a sophisticated data collection platform [14]. However, the data transmission restrictions resulting from energy constraints and Argos restrictions do not interact in an additive way and steps taken to get around Argos limitations can also serve to help avoid energy constraints [14].

An improvement in the data transfer rate may be achieved in the future if Argos' plans to facilitate 2way communication materialize in a form applicable to very small platforms or if the Argos system is replaced with Iridium, which allows much faster data transfer. Additionally, 2-way communication will be possible. But Iridium units are still too large to be integrated into existing animal-borne instruments and are also energy demanding. Other drawbacks of the Iridium system include the required modem synchronization and handshake procedures. These will have to be shortened to fit into the short surface intervals of some marine species if the system is to be useful for near real time data-relay from the sea

Another communication system that is being utilized by biologging practitioners is the GSM mobile phone system, which is already being used for studies of marine species that come near shore [22]. In this sort of data-logger, data are stored in an internal memory, which can be relayed via the mobile phone system, when the animals are close to shore where mobile phone service is available. Because such visits ashore may be infrequent, instruments store up to six months of data. These data can also be downloaded directly if the instrument is retrieved1. GSM data-relay offers high data bandwidth and is over one hundred times more energy efficient than Argos. Modern instruments use quad-band ensuring that the tag operates on all continents, wherever GSM coverage is available.

A further constraint of the Argos system is that the highest quality location is $150 \mathrm{~m}$, but such locations are very rare from animals at sea and are often only within
$1 \mathrm{~km}$ or greater. While GPS tags ${ }^{3}$ are now available for marine animals that can provide locations within $10 \mathrm{~m}$, this capability has yet to be incorporated into a tag carrying a CTD sensor. However, transmitting additional location data also implies the need for a higher data transfer rate, which is currently only achievable using e.g. Iridium or GSM.

\subsection{Sensor performance}

The design requirements for an animal-borne oceanographic sensor head are that it must use little power, be virtually indestructible, and yet be minimized in size and weight. This requires small sensors that are less accurate when compared to larger pumped CTDs.

The basic question that needs to be addressed is the necessary accuracy of the oceanographic sensors to be useful for oceanography. Recent studies show that the ocean temperatures have warmed by more than $0.1^{\circ} \mathrm{C}$ over the last 50 years [23], but long-term changes in the ocean temperatures are usually of the order of $0.01^{\circ} \mathrm{C}$ per decade [20 and 24]. So, to incorporate ocean temperature and salinity data into oceanographic datasets the accuracy should be in the order of 0.1 , but to play a role in the study of global climate change the accuracy needs to be better by at least one order of magnitude.

Most animal-borne oceanographic instruments deliver vertical profiles similar to expendable bathythermographs (XBTs), which are traditionally used to provide an ocean temperature versus depth profile with an accuracy of $\pm 0.02^{\circ} \mathrm{C}$ to $\pm 0.1^{\circ} \mathrm{C}$ [25]. So, in order for animal-borne sensor data to be of use to the oceanographic community for long-term change purposes, proven accuracies of \pm 0.02 for salinity and $\pm 0.02^{\circ} \mathrm{C}$ for temperature are necessary. While these sensor accuracies in themselves are quite easily achievable, they must be attained in combination with the other requirements.

Some animal-borne instruments use an aged bead thermistor with a negative temperature coefficient, hermetically sealed in the tip of a shock resistant solid glass rod to measure ocean temperature. While the resistance versus temperature characteristic of such thermistors is a nonlinear, negative exponential function, it can be very accurately described by the Steinhart-Hart equation. Assuming the thermistor is well aged and that good calibration data are available, such thermistors can measure temperature with errors less then $\pm 0.05^{\circ} \mathrm{C}$. State-of-the-art animal-borne CTDs use a platinum resistance temperature detector (PRT) for greater accuracy. The PRT works on the principle

\footnotetext{
${ }^{3}$ http://www.smru.standrews.ac.uk/protected/downloads/GPS_Phone_Tag22.pdf info@wildtracker.com
} 
of resistance through a fine platinum wire as a function of temperature. This probe is normally housed in a metal tube in front of the conductivity sensor. For example, the PRT of the CTD-SRDL built by the Sea Mammal Research Unit is lab calibrated by Valeport $\mathrm{Ltd}$, Devon, UK to accuracy better than $\pm 0.005^{\circ} \mathrm{C}$.

Salinity is derived from such temperature measurements and simultaneous recordings of conductivity. To sample conductivity the inductive method has proven to be superior over an electrode. Titanium and ceramic construction and new digital measurement techniques result in durable and highly accurate sensors with much lower power consumption than traditional methods, and with much shorter sampling duration. Animal-borne sensors can now record conductivity with accuracy better than $\pm 0.005 \mathrm{mScm}$
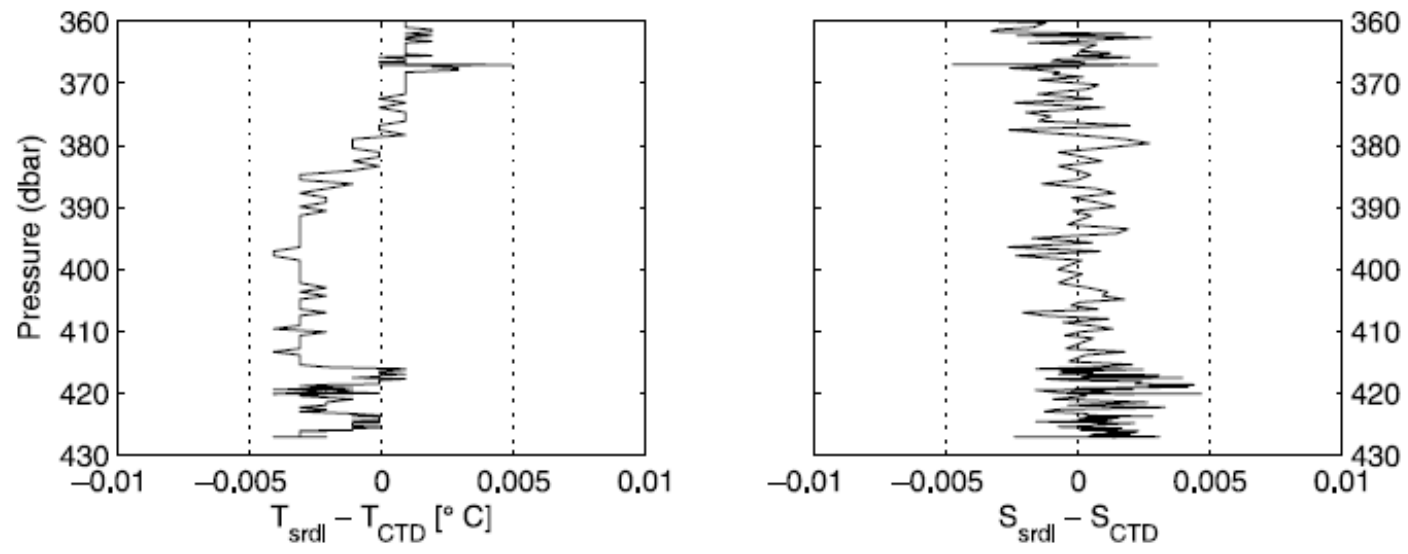

Figure 4. Differences in temperature (left) and salinity (right) of a CTD-SDRL and a ship-based CTD. The CTD-SRDL was attached to the frame of the ship-based instrument. Only measurements taken in a relatively homogeneous water mass are used [8]

These accuracies have been confirmed by checks against ship-based CTD systems. Boehme et al. [8]) and Nicholls et al. [17] estimated the absolute uncertainty in temperature and salinity data to be $0.005^{\circ} \mathrm{C}$ and 0.02 respectively (Fig. 4). Thus, animalborne instruments have now been proven to be sufficiently accurate to be a useful complement to ocean observing systems.

\subsection{Other sensors}

TOPP has recently demonstrated the concept of estimating in situ chlorophyll concentration profiles from light level and depth data collected by electronic tags [27] using a bio-optical model. More information about these measurements is contained in the white paper by Costa et al [16].

New developments within the MEOP project involve an optional fluorometer attached to a CTD-SRDL. These instruments were successfully tested on southern elephant seals on Kerguelen in 2008 and 2009. More information about these instruments is contained in the white paper by Charrassin et al. [28].

\section{DATA FLOW}

Most research projects gathering oceanographic data with animal-borne sensors are making their ocean data freely available. Some employ a temporal restriction, while others make data available in near real-time. Here, we will present an example of a possible data flow in near-real time adapted for the MEOP project. All MEOP data are being distributed via the World Meteorological Organization (WMO) Global Telecommunication System (GTS). This system started working at the beginning of July 2008 and is part of the UK project Oceans 2025 (Fig. 5).

Behavioural and CTD data are transmitted from the animal-borne instruments to the Argos satellite system and then received by a ground station. Upon receiving messages from the tag, the Argos system computes the animal's location and sends it and the data to the Sea Mammal Research Unit where it is decoded and presented to users in a password restricted web interface. The bare CTD data are then forwarded to the British Oceanographic Data Centre (BODC). The BODC converts the data into the TESAC format, which is a Traditional Alphanumeric Code (TAC). These data are then forwarded to the UK Met Office (UK GTS node) and placed onto the GTS. Depending on the number of active animal-borne instruments, up to 150 CTD profiles were forwarded per day from high latitudes (Fig. 1).

In the future, the use of BUFR (Binary Universal Form for the Representation of meteorological data) for encoding the CTD data might be more useful, so that 
quality flags among other things can be included. At the moment, no real-time quality control system is place, but we are presently adopting quality control procedures similar to those used in the Argo float community to ensure the high quality of the real-time data. A delayed-mode quality control system will also be established in the near future.

The TOPP project has partnered with Google to create GTOPP.org a site that will also make ocean data from multiple animals freely available in 2009. For data handling in this program, the plan is to quality control data prior to making it available on the GTOPP website.

\section{ETHICAL ISSUES}

It is the view of the authors that tagging of marine mammals is acceptable only if the resulting behavioural and ecological data advances the science, management and conservation of the species involved. Although some of the research involving animal-borne sensors is motivated by an oceanographic need, the proposals to enlist marine mammals have always been contingent on the belief that the study will further the understanding of the importance of the oceanographic environment to the reproductive success and general well-being of marine mammals. Understanding the

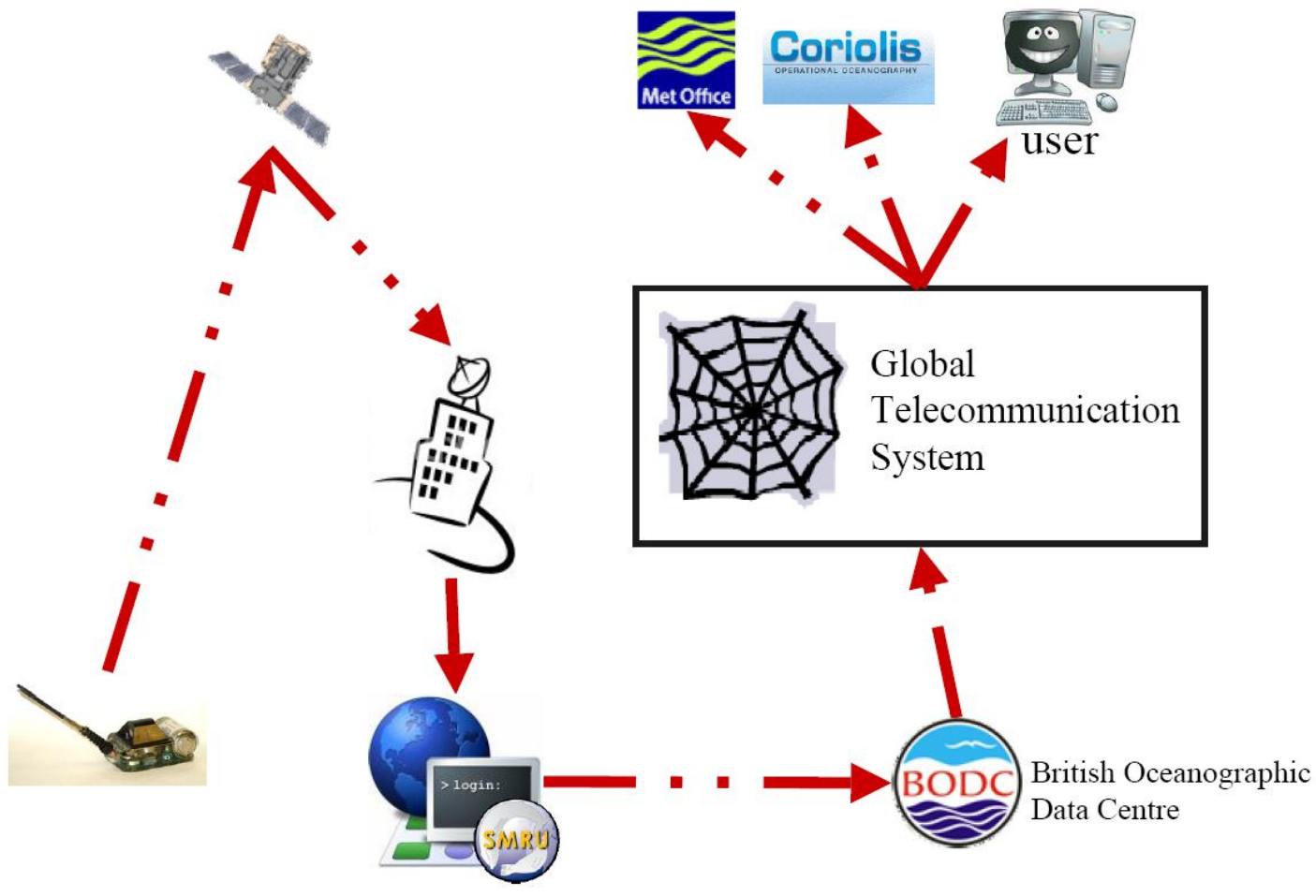

Figure 5. Data flow in the ongoing MEOP project. Data are broadcast from the instrument and received by the ARGO satellite system. Then decoded and forwarded to the BODC Data.

oceanographic context for a successful population/individual brings us a step closer to managing the oceans with the best possible stewardship for the animals that depend on them for survival.

\section{CONCLUSIONS}

Two issues will determine the future of animal-borne sensors in the ocean observing system during the next decade. Firstly, we have to improve the efficiency and sensor performance. The second question is how animal-borne sensors will be combined with other autonomous instrumentation types, especially floats and gliders in a comprehensive ocean observing system.
In this paper we showed both the limitations and the strengths of animal-borne sensors in providing ocean observations. The main constraints are power consumption and instrument size. The size limits the use of 'off the shelf' sensors. Nevertheless, we are well on the way to developing new sensors as add-ons to existing systems. In the future, manufacturers will either incorporate additional sensors into an existing CTD head or provide complete new sensor heads and/or instruments that focus on other biochemical measurements or even make sensors to detect the presence of other marine species.

The data quality of current animal-borne sensors is high and the data derived from them are already providing useful ocean observing systems in the 
Southern Ocean [6 and 18]. Systematic deployments in the future could make animal-borne systems important additions to global ocean observation strategies [29 and 30].

Animal-borne sensors have a range of advantages and limitations when incorporated into ocean observing systems. For example, their spatial range depends on the chosen animal species, and they can deliver both broad- and small-scale observations. However, they are limited somewhat by physical features that preclude animals using them as a habitat, e.g. they cannot deliver data from below ice shelves, where e.g. gliders and AUVs can be used to get high-resolution data.

The main advantages for observing systems to integrate animal-borne sensors are:

- Wintertime transects in high latitudes, when shipbased measurements are scarce.

- Measurements close to or below sea ice.

- Time series in areas of ocean currents or upwelling zones in which Argo floats get advected away.

- Increased number of in situ ocean data without increasing the carbon footprint of the observing system.

It is clear that the observing systems of the near future should use combinations of approaches that deliver the required data most effectively in cost-efficient ways. The animal-born platforms will provide an important complimentary role in such systems.

Another important product of these deployments is the provision of unique, linked biological and physical datasets. These can be used by marine biologists, who study these animals but also by biological oceanographers. By incorporating animal-borne sensors into ocean observing systems, we not only gain information about global ocean circulation and enhance our understanding of climate and the corresponding heat and salt transports, but at the same time we increase our knowledge about the life history of ocean's top predators and their sensitivity to climate change as promote an ecosystem approach within oceanography.

\section{REFERENCES}

1. Evans, W.E. (1970). Uses of advanced space technology and upgrading the future of oceanography. American Institute of Aeronautics and Astronautics Paper No. 7$01273.3 \mathrm{pp}$.

2. Block, B.A., D. Costa, G. Boelhert, R. Kochevar (2003), Revealing pelagic habitat use: The tagging of Pacific Pelagics. Oceanographic Acta 25: 255-266.
3. Fedak, K. (2004), Marine animals as platforms for oceanographic sampling: a "win/win" situation for biology and operational oceanography. Mem. Natl Inst. Polar Res., Spec. Issue, 58, 133-147.

4. Biuw, M., et al. (2007), Variations in behavior and condition of a Southern Ocean top predator in relation to in situ oceanographic conditions. Proc. Natl. Acad. Sci. U.S.A., 104, 13,705 - 13,710, doi:10.1073/pnas.0701121104.

5. Boehlert, G.W., D.P. Costa, D.E. Crocker, P. Green, T. O'Brien, S. Levitus, and B.J. Le Boeuf, (2001), Autonomous Pinniped Environmental Samplers: Using Instrumented Animals as Oceanographic Data Collectors. J. Atmos. Oceanic Technol., 18, 18821893.

6. Charrassin, J.B., Y.H. Park, Y. Le Maho, C.A. Bost (2002), Penguins as oceanographers unravel hidden mechanisms of marine productivity. Ecology Letters, 5: 317-319.

7. Lydersen, C., O.A. Nøst, P. Lovell, B.J. McConnell, T. Gammelsrød, C. Hunter, M.A. Fedak, K.M. Kovacs (2002), Salinity and temperature structure of a freezing Arctic fjord monitored by white whales (Delphinapterus leucas). Geophys. Res. Lett., 29(23), 2119, doi:10.1029/2002GL015462.

8. Boehme, L., M.P. Meredith, S.E. Thorpe, M. Biuw, M. Fedak (2008a), Antarctic Circumpolar Current frontal system in the South Atlantic: Monitoring using merged Argo and animal-borne sensor data. J. Geophys. Res., 113, C09012, doi:10.1029/2007JC004647.

9. Charrassin, J. B., et al. (2008), Southern Ocean Frontal Structure and Sea-Ice Formation Rates Revealed by Elephant Seals. Proc. Natl. Acad. Sci. U.S.A. 105:11634-9.

10. Costa, D.P., J. Klinck, E.E. Hofmann, M. Dinniman, J.M. Burns (2008), Upper ocean variability in west Antarctic Peninsula continental shelf waters as measured using instrumented seals. Deep-Sea Research II, 55, 323-337

11. Boyd, I.L., E.J. Hawker, M.A. Brandon, I.J. Staniland (2001), Measurement of the ocean temperatures using instruments carried by Antarctic fur seals. Journal of Marine Systems, 27, 277-288.

12. Charrassin, J.B., Y.H. Park, Y. Le Maho, C.A. Bost (2004), Fine resolution 3D temperature fields off Kerguelen from instrumented penguins. Deep-Sea Research I, 51, 2091-2103.

13. Sokolov S., S.R. Rintoul, B. Wienecke (2006), Tracking the Polar Front south of New Zealand using penguin dive data. Deep Sea Research Part I, 53 (4), 591-607, doi:10.1016/j.dsr.2005.12.012.

14. Fedak, M., P. Lovell, B. McConnell, C. Hunter (2002), Overcoming the Constraints of Long Range Radio Telemetry from Animals: Getting More Useful Data from Smaller Packages. Integ. And Comp. Biol., 42, 310. 
15. Lydersen, C., O.A. Nøst, K.M. Kovacs, M.A. Fedak (2004), Temperature data from Norwegian and Russian waters of the northern Barents Sea collected by freeliving ringed seals. Journal of Marine Systems, 46, 99108 .

16. Costa, D., Block, B., Bograd, S., Fedak, M. and Gunn, J., (2010). "TOPP as a Marine Life Observatory: Using Electronic Tags to Monitor the Movements, Behaviour and Habitats of Marine Vertebrates" in these proceedings (Vol. 2), doi:10.5270/OceanObs09.cwp.19.

17. Nicholls, K.W., L. Boehme, M. Biuw, M.A. Fedak (2008), Wintertime ocean conditions over the southern Weddell Sea continental shelf, Antarctica. Geophys. Res. Lett., 35, L21605, doi:10.1029/2008GL035742.

18. Meredith, M.P., K.W. Nicholls, I.A. Renfrew, L. Boehme, M. Biuw, M. Fedak (2009), Seasonal evolution of the upper-ocean adjacent to the South Orkney Islands, Southern Ocean: results from a "lazy biological mooring". Deep Sea Research Part II, in press, doi:10.1016/j.dsr2.2009.07.008.

19. Boehme, L., S.E. Thorpe, M. Biuw, M. Fedak, M.P. Meredith (2008b), Monitoring Drake Passage with elephant seals: Frontal structures and snapshots of transport. Limnology \& Oceanography, 53, 2350-2360.

20. Boyd, J. D. and R. Linzell (1993), The Temperature and Depth Accuracy of Sippican T-5 XBTs. Journal of Atmospheric and Oceanic Technology, 10, 128-136.

21. Argos, (1996), Argos User's Manual. Collecte Localisation Satellites (CLS).

22. McConnell, B.J., R. Beaton, E. Bryant, C. Hunter, P. Lovell, A.J. Hall (2004); Phoning home - a new GSM mobile phone telemetry system to collect markrecapture data. Marine Mammal Science, 20:274-283.

23. Gille, S. T. (2002), Warming of the southern ocean since the 1950s. Science, 295, 1275-1277.

24. Zenk, W., E. Morozov, A. Sokov, T.J. Müller (2003) Vema Channel: Antarctic bottom water temperatures continue to rise., CLIVAR Exchanges, 8, 24-26.

25. Fukasawa, M., H. Freeland, R. Perkin, T. Watanabe, H. Uchida, A. Nishina (2004), Bottom water warming in the North Pacific Ocean., Nature, 427, 825-827.

26. Boehme, L., M. Biuw, M. Fedak, K. Nicholls, S. Thopre, M. Meredith (2008c), Animals as exploratory underwater vehicles. Proceedings of the International Workshop on Autonomous Underwater Vehicle Science in Extreme Environments held at the Scott Polar Research Institute, K.J. Collins and G. Griffiths, eds., London: Society for Underwater Technology, pp 55-62.

27. Teo SLH, Kudela RM, Rais A, Perle C, Costa DP, Block BA (2009) Estimating chlorophyll profiles from electronic tags deployed on pelagic animals. Aquat Biol 5:195-207, doi:10.3354/ab00152.

28. Charrassin, J. \& Co-Authors (2010). "New Insights into Southern Ocean Physical and Biological Processes
Revealed by Instrumented Elephant Seals" in these proceedings (Vol. 2), doi:10.5270/OceanObs09.cwp.15.

29. Rintoul, S. \& Co-Authors (2010). "Southern Ocean Observing System (SOOS): Rationale and Strategy for Sustained Observations of the Southern Ocean" in these proceedings (Vol. 2), doi:10.5270/OceanObs09.cwp.74.

30. Gunn, J., Rogers, A. and Urban, E., (2010). "Observation of Ocean Biology on a Global Scale: Implementing Bio-GOOS?" in these proceedings (Vol. 1), doi:10.5270/OceanObs09.pp.20. 